\title{
Influence of the Dopants on the Mechanical Properties of Alumina-Based Ceramics
}

\author{
Anton Sergeevich Kaygorodov, Vasily Ivanovich Krutikov, and Sergey Nikolaevich Paranin
}

Institute of Electrophysics UD RAS, Amundsen Street, 106, Yekaterinburg 620016, Russia

Correspondence should be addressed to Anton Sergeevich Kaygorodov; kaigor@iep.uran.ru

Received 29 September 2013; Revised 30 October 2013; Accepted 11 November 2013

Academic Editor: Young-Wook Kim

Copyright (C) 2013 Anton Sergeevich Kaygorodov et al. This is an open access article distributed under the Creative Commons Attribution License, which permits unrestricted use, distribution, and reproduction in any medium, provided the original work is properly cited.

\begin{abstract}
In the present study the mechanical properties of dense alumina-based ceramics obtained by two processing routes are investigated. The application of magnetic-pulsed compaction or hot pressing of the powder leads to a comparable combination of microhardness, elastic modulus, and fracture toughness. The insertion of $\mathrm{Al}$ into $\mathrm{Al}_{2} \mathrm{O}_{3}$ powder increases the microdistortions of the crystalline lattice, resulting in the sufficient decrease of indentation wear-resistance. The usage of $\mathrm{ZrO}_{2}$ or TiCN as dopants to alumina matrix improves slightly the mechanics of the composites with a noticeable decrease of the material lost by $30 \%$ compared to pure alumina at closely spaced arrays of indents. Regardless of the synthesis method, the ceramic grains were formed completely with the fracture travelling along the grain boundaries.
\end{abstract}

\section{Introduction}

Due to the combination of high hardness, heat resistance, chemical inertia on the one hand, and accessibility on the other, alumina appears to be the a material for a wide range of structural applications with energy-tense service conditions. Particularly, it is advisable to develop $\mathrm{Al}_{2} \mathrm{O}_{3}$-based ceramics for the production of critical wear-resistant machine parts, which are exposed to intensive erosion and abrasive and impact action, including corrosive mediums. However, the traditional alumina-based ceramics with coarse-grained structure are very brittle and sensitive to the destructive mechanical effect. This limits its wear-resistant use sufficiently. The fabrication and application of resistant alumina ceramics will lead to multiple increasing of service characteristics covering a wide range of technological objects, such as dry friction pairs, jet-forming nozzles for hydroabrasive cutting, and protective coatings for metallic parts. It is well known that sufficient increase of ceramics wear-resistance can be realized by the synthesis of the material with uniform fine structure $[1,2]$. It is important to fabricate ceramics with the smallest nanometer structural scale length, high homogeneity, minimal porosity, and well-formed intercrystalline boundaries having the defined phase composition [3]. These conditions provide high fracture toughness and hardness of the ceramics.

There are several methods to obtain ceramics with fine structure. It was shown in [2] that the addition of $11 \mathrm{wt} . \%$ $\mathrm{ZrO}_{2}$ to alumina powder leads to the sufficient structural scale length decrease and to the increase of abrasive wear resistance by a factor of three. It was shown by the authors that $\mathrm{MgO}, \mathrm{TiO}_{2}$, or $\mathrm{ZrO}_{2}$ doped alumina ceramics possess higher abrasive-erosion wear resistance. In order to stabilize the nanocrystal structure, it is also possible to use some metals (Ni and Fe, e.g.) [4-6]. The presence of some soft metallic fraction improves the powder compaction and minimizes the microstresses inside the ceramic samples. In case of alumina powder the most interesting additive appears to be aluminum, being oxidized during the reacting sintering with the formation of monolithic alumina ceramics [7]. On the other hand there are some methods, like two-stage sintering [8] and the usage of nontraditional high-energy compaction methods with the following sintering, that provide the fabrication of the fine-grained ceramics. In particular, the magnetic-pulsed compaction method [9] that is used in this work allows for effectively compacting alumina nanopowders up to $70 \%$ of the theoretical density and to obtaining homogeneous green bodies that are suitable to sintering at relatively low 
TABLE 1: The main characteristics of the starting powders.

\begin{tabular}{lccc}
\hline Powder & Phase content (wt.\%) & $d(\mathrm{~nm})$ & Supplier \\
\hline $\mathrm{AO}$ & $\alpha-\mathrm{Al}_{2} \mathrm{O}_{3}-100$ & 150 & Inframat Advanced Materials \\
$\mathrm{Al}_{2} \mathrm{O}_{3}$ & $\alpha-\mathrm{Al}_{2} \mathrm{O}_{3}-100$ & $<1000$ & Baikowski \\
$\mathrm{Al}$ & $\mathrm{Al}-84$ & & \\
& $\mathrm{MgO}-1$ & 154 & Institute of Electrophysics, Russia \\
$\mathrm{ZrO}_{2}$ & $\mathrm{Al}_{2} \mathrm{O}_{3}$ (amorphous) -15 & 27 & Tosoh \\
$\mathrm{TiCN}$ & $\mathrm{ZrO}_{2}$ (monoclinic) -100 & $1000-1300$ & H.C. Starck \\
\hline
\end{tabular}

TABLE 2: The main characteristics of the powder mixtures.

\begin{tabular}{|c|c|c|}
\hline Mixture & Chemical content (wt.\%) & Alumina supplier \\
\hline $\mathrm{AO} 13 \mathrm{Al}$ & $\begin{array}{c}\mathrm{Al}_{2} \mathrm{O}_{3}-87 \\
\mathrm{Al}-12.8 \\
\mathrm{Mg}-0.2\end{array}$ & Inframat Advanced Materials \\
\hline $\mathrm{AO} 25 \mathrm{Al}$ & $\begin{array}{l}\mathrm{Al}_{2} \mathrm{O}_{3}-75 \\
\mathrm{Al}-24.7 \\
\mathrm{Mg}-0.3\end{array}$ & Inframat Advanced Materials \\
\hline $\mathrm{AlO}_{x} \mathrm{Z}$ & $\begin{array}{l}\mathrm{Al}_{2} \mathrm{O}_{3}-70 \\
\mathrm{ZrO}_{2}-30\end{array}$ & Baikowski \\
\hline $\mathrm{AlO}_{x} \mathrm{~T}$ & $\begin{array}{l}\mathrm{Al}_{2} \mathrm{O}_{3}-60 \\
\mathrm{TiCN}-40\end{array}$ & Baikowski \\
\hline
\end{tabular}

temperatures. Therefore, in this work the fabrication of alumina ceramics with improved mechanical properties from the composite alumina nanopowders with aluminum and some oxides additives was investigated and the comparison of their wear resistance modeled by indentation method was made.

\section{Materials and Methods}

The initial powders that were used in this work are summarized in Table 1 . Here one can find the designation of the powder used in this work, the phase content of the powder, its average particle size, $d$, and the supplier for each type of powder.

The mechanical mixing of different amounts of $\mathrm{AO}$ and $\mathrm{Al}$ nanopowders in isopropyl alcohol under ultrasonic activation was used to prepare $\mathrm{Al}_{2} \mathrm{O}_{3} / \mathrm{Al}$ powders (Table 2). The as-prepared powders were compacted into $15 \times 2 \mathrm{~mm}$ discs using uniaxial magnetic-pulsed press (MPC) with the pressure of 1.6 GPa in the amplitude [9]. The compaction was performed at room temperature after vacuum (residual pressure $\sim 10 \mathrm{~Pa})$ hot $\left(400^{\circ} \mathrm{C}\right)$ degassing in order to eliminate the adsorbed gases from the powder. After pulsed action the samples were heated up to $400^{\circ} \mathrm{C}$ to reduce the internal stresses inside the compacts. The green bodies were sintered in the resistive furnace in air at $1550^{\circ} \mathrm{C}$ for $30 \mathrm{~min}$ with heating/cooling rate of $5^{\circ} \mathrm{C} / \mathrm{min}$. The $\mathrm{X}$-ray analysis showed that such heat treatment of the composite powder mixture leads to a complete transformation of $\mathrm{Al}$ to $\mathrm{Al}_{2} \mathrm{O}_{3}$ due to the internal oxidation of the metal at high temperatures.

For the set of alumina-based composites the appropriate amount of $\mathrm{ZrO}_{2}$ and TiCN was mixed with $\mathrm{Al}_{2} \mathrm{O}_{3}$ on a multidirectional Turbula mixer (type T2A, Basel, Switzerland) in ethanol in a polyethylene container of $250 \mathrm{ml}$ during $24 \mathrm{~h}$ at $60 \mathrm{rpm} .250$ grams zirconia milling balls (Tosoh grade TZ-3Y, Japan) with a diameter of $3 \mathrm{~mm}$ were added to the container to break the agglomerates in the starting powder and to enhance powder mixing. The ethanol was removed after mixing using a rotating evaporator. The dry powder mixture was placed into a graphite die/punch set-up $(\simeq 43 \mathrm{~mm})$ and coated manually with the boron nitride to avoid carbon diffusion and sample-die sticking. After cold compression at $30 \mathrm{MPa}$, the samples were hot pressed (HP) (Model W 100/150-2200-50 LAX, FCT System, Germany) in vacuum for $1 \mathrm{~h}$ under a mechanical load of $28 \mathrm{MPa}$ at $1450^{\circ} \mathrm{C}$, with a heating rate of $50^{\circ} \mathrm{C} / \mathrm{min}$ and a cooling rate of $10^{\circ} \mathrm{C} / \mathrm{min}$.

The density of the green bodies and the ceramic samples was determined by Archimedes method. The data scattering in all density measurements did not exceed $1 \%$. The microstructure of the materials was investigated by SEM (LEO 982). The average grain size was determined by the intersection method over at least 5 SEM images. The X-ray analysis was performed at DRON-4 device in the filtered $\mathrm{CuK} \alpha$ radiation. The mechanical properties of the ceramics were studied by the indentation method (Nanotest 600). The microhardness, elastic modulus, and fracture toughness of the ceramics were investigated by Vickers indenter at average loads of 2 and $7 \mathrm{~N}$, correspondingly. In case of fracture toughness tests the surface was polished with diamond pastes up to the roughness of about $0.025 \mu \mathrm{m}$. The indentation toughness, $K_{\mathrm{IC}}$, based on the crack length measurement of the radial crack pattern produced by Vickers indentations, was calculated according to the formula of Anstis et al. [10]. The reported hardness, elastic modulus, and toughness values are the mean and standard deviation obtained from five indentations. 
TABLE 3: The mechanical properties of the alumina-based ceramics.

\begin{tabular}{ccccccccc}
\hline \multicolumn{2}{c}{ Ceramics } & Processing method & $\gamma_{\text {rel }}(\%)$ & $d_{\mathrm{gr}}(\mu \mathrm{m})$ & $E(\mathrm{GPa})$ & $H_{V}(\mathrm{GPa})$ & $K_{\mathrm{IC}}\left(\mathrm{MPa} \cdot \mathrm{m}^{0,5}\right)$ & $\Delta d / d(\%)$ \\
\hline \multirow{6}{*}{ Alumina } & $\mathrm{AO}$ & 97 & 2.5 & 386 & 18.9 & 5.8 & 0 \\
\multirow{6}{*}{ Composite } & $\mathrm{AO} 13 \mathrm{Al}$ & $\mathrm{MPC}+$ sintering & 98 & 1.7 & 364 & 19.4 & 6.2 & 0.3 \\
& $\mathrm{AO} 25 \mathrm{Al}$ & & 97 & 0.8 & 332 & 18.7 & 5.4 & 0.5 \\
& $\mathrm{AlOx}$ & & 95 & 2.2 & 292 & 16.0 & 5.4 & - \\
& $\mathrm{AlO}_{x} \mathrm{Z}$ & $\mathrm{HP}$ & 97 & 0.8 & 316 & 16.9 & 5.0 & - \\
& $\mathrm{AlO}_{x} \mathrm{~T}$ & & 96 & 0.5 & 412 & 20.1 & 4.4 & - \\
\hline
\end{tabular}

Here, $\gamma_{\text {rel }}:$ relative density; $d_{\mathrm{gr}}$ : average grain size; $E, H_{V}$, and $K_{\mathrm{IC}}$ : Young's modulus, microhardness, and fracture toughness of the ceramics, correspondingly; $\Delta d / d$ : microdistortion of the crystalline lattice.

The erosive wear of the ceramics was modeled by arrays of indentations. Indentations were made using a Berkovich indenter. Sets of 9 indentations were made in square arrays with the central indentation made last. Arrays were made with indentation spacing of up to $50 \mu \mathrm{m}$ with $200 \mu \mathrm{m}$ gaps between grids repeated 3 times for each material. The indentation load was set as $4.9 \mathrm{~N}$. This load is an appropriate load for damage to interact at a suitable spacing to be observed in an optical microscope and is of the same order as the load that Franco and Roberts [11] estimate as equivalent to the impact force of erosive particles under the conditions used in this work. Loading and unloading took $20 \mathrm{~s}$ with a $5 \mathrm{~s}$ hold period at maximum load. An optical microscope (Olympus BX-41M) was used to measure the volume of the material lost due to fracture within and around each set of 9 indentations. The instrument registered the data from 5 focal scans to produce a height map. After that the volume below the plane of the undisturbed surface outside the indentation grid was calculated. This volume represents the volume of material lost from the surface due to fracture plus the volume of the 9 indentations. The volume of material lost was averaged for the 3 grids at each spacing.

\section{Results and Discussion}

It is known [3] that the mechanical properties, microhardness, and fracture toughness, in particular, depend sufficiently on the ceramics' density and structural scale length. As one can see from Table 3 the addition of the second phase to pure alumina leads to the decrease of the average grain size of composites with the comparable mechanical properties.

Among the alumina ceramics obtained in this work $\mathrm{AO} 13 \mathrm{Al}$ had the best combination of the mechanical properties, namely, $H_{V}$ and $K_{\mathrm{IC}}$. This goes in controversy with the fact that smaller length scale should result in the improvement of the mechanical properties. Thus, the highest $H_{V}$ and $K_{\mathrm{IC}}$ values were expected for $\mathrm{AO} 25 \mathrm{Al}$ ceramics as it had smaller grains. In order to explain that, one might want to analyze the level of microdistortion of the crystalline lattice of the $\mathrm{AO} / \mathrm{Al}$ ceramics (Table 3 ). According to $\mathrm{X}$-ray analysis, the insertion of $\mathrm{Al}$ into the initial $\mathrm{AO}$ powder leads to a rapid increase of the interplanar change in the corundum lattice. This effect is more severe the larger the amount of $\mathrm{Al}$ is in the initial powder mixture.

The analysis of differently processed alumina ceramics from pure $\mathrm{Al}_{2} \mathrm{O}_{3}$ powders shows that the usage of MPC during synthesis leads to more homogeneous microstructure with the comparable average grain size of both ceramics (Figures 1(a) and 1(b)). In both cases the crystallites are formed completely and the fracture travels along the grain boundaries mainly.

The addition of $\mathrm{Al}$ to $\mathrm{AO}$ powder leads to the decrease in the grain size of sintered ceramics (Figures 1(a), 1(b), and $1(\mathrm{c})$ ). This is connected with the mechanism of thermal compression of aluminum, namely, with the expansion of a metal core inside the tough alumina shell [12]. Here two fractions were found: a coarse one, $2-3 \mu \mathrm{m}$, inherited from the alumina powder particles and the fine one, $100-300 \mathrm{~nm}$, formed as a result of internal oxidation of metal particles. The increase of the metallic content in the initial powder leads to a proportional increase of the relative fraction of fine structure in the ceramics (Figures 1(b) and 1(c)). It should be noted that one should pay attention to the distribution of the structural elements in the sintered ceramics while choosing the initial powders. The $25 \mathrm{wt} . \%$ addition of aluminum gives more homogeneous structure with the developed relief (Figure 1(d)) compared to the ceramics from AO13Al mixture (Figure 1(c)).

The same tendency of the microstructural scale length decrease is found for the $\mathrm{AlO}_{x} \mathrm{Z}$ and $\mathrm{AlO}_{x} \mathrm{~T}$ composites (Figures 1(b), 1(e), and 1(f)). This is due to the elimination of the abnormal grain growth upon sintering by the segregation of the dopant on the grain boundaries of the matrix phase [13].

The indentation modeling of wear resistance revealed that the change of the indentation parameters leads to a different mechanism of the sample's surface modification. This was clearly detected by the optical microscope. Figure 2 presents the change of the surface with the variation of array spacing parameters: (a, c)-elastic-plastic deformation and (b)-additional material lost. Relating to [14] the impression volume was taken into account. That is why the decrease of the spacing from 50 down to $0 \mu \mathrm{m}$ led to three characteristic stages of the qualitative change of the macrodamage of the surface: $\left(\mathrm{V}_{1}\right)$-the array, consisting of 9 separate indents (in some cases there were cracks, stretching from the corners of the indent) (Figure 2(a)); $\left(\mathrm{V}_{2}\right)$-chipping of the material due to the intersection of the cracks and/or the internal stress regions (Figure 2(b)); $\left(\mathrm{V}_{3}\right)$-a single impression, after the consequent penetration of the indenter for 9 times on the same point of the surface (Figure 2(c)). It should be noted that due to the fatigue behavior of the ceramics the volume $\left(\mathrm{V}_{1}\right)$ was $5-10 \%$ smaller than 9 times the volume $\left(\mathrm{V}_{3}\right)$. 


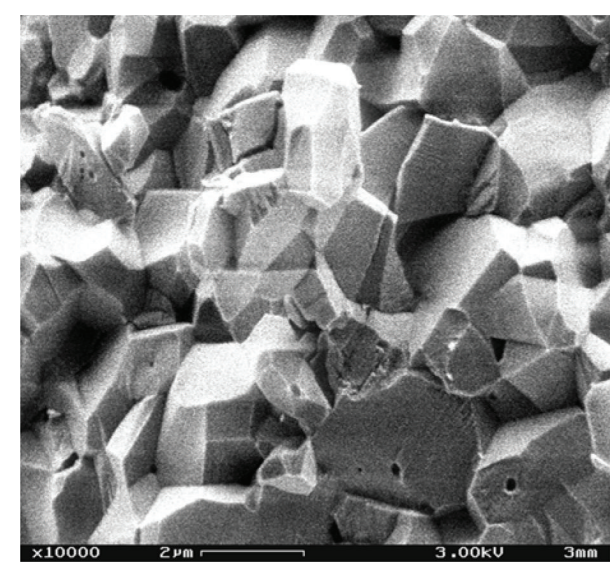

(a)

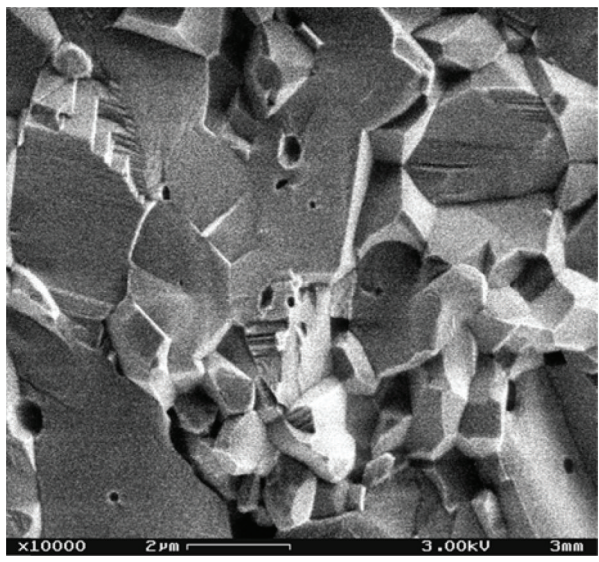

(c)

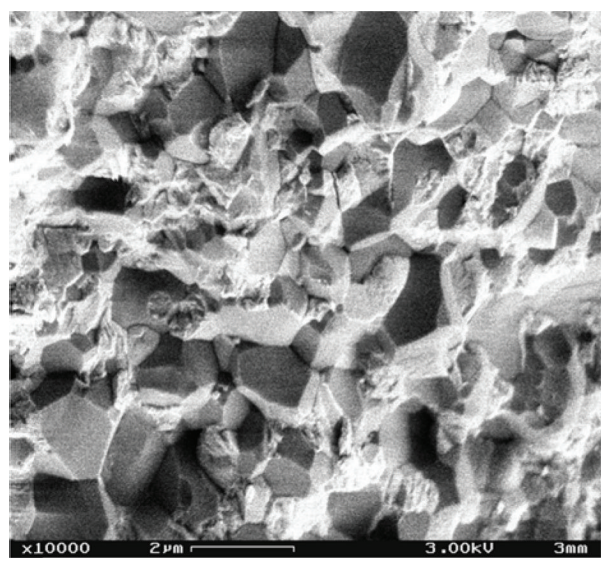

(e)

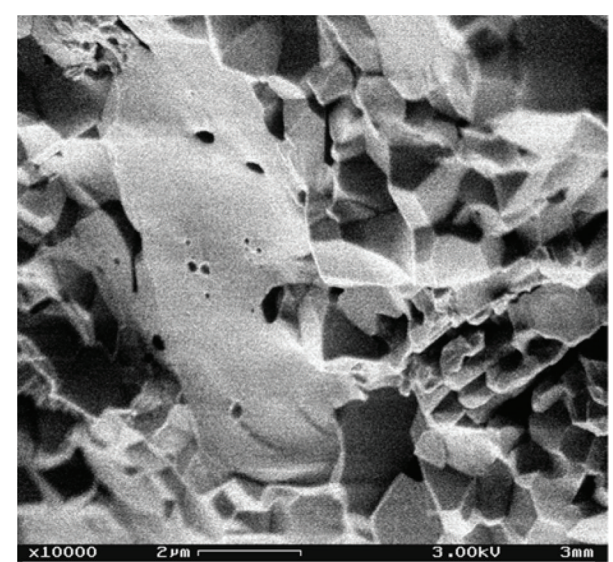

(b)

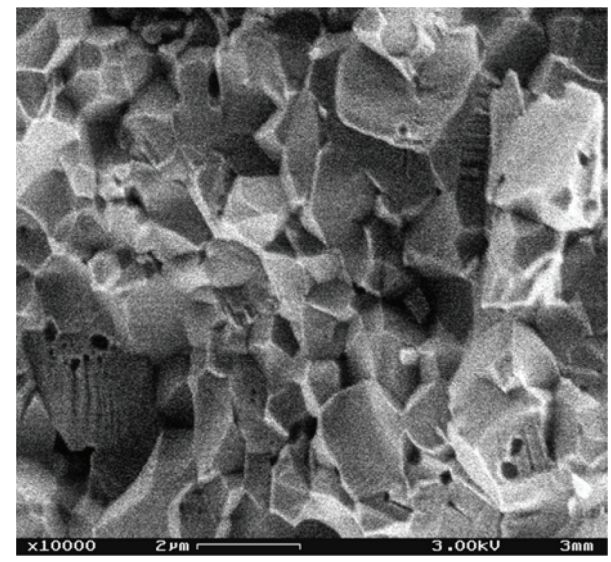

(d)

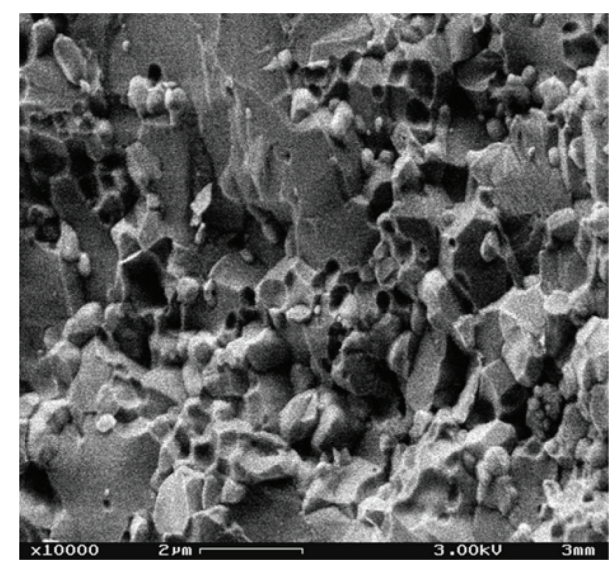

(f)

FIGURE 1: SEM images of the fracture of (a)-AO, (b)-AlOx, (c)-AO13Al, (d)-AO25Al, (e)- $\mathrm{AlO}_{x} \mathrm{Z}$, and (f)- $\mathrm{AlO}_{x} \mathrm{~T}$ ceramics.

The quantitative change of the surface damage depending on the array spacing is given in Figure 3.

It turned out that in case of $\mathrm{AO} / \mathrm{Al}$ ceramics the amount of the metal in the initial powder plays a sufficient role at material chipping from the surface of the sample. Here the presence of $13 \%$ of $\mathrm{Al}$ in the starting powder leads to a slight decrease of the volume loss at critical distances of 20-24 $\mu \mathrm{m}$ (curves 1 and 2). At the same time the addition of $25 \%$ of metal decreased the indentation wear resistance in the whole range of the distances between the indents (curves 1 and 3 ). This can be explained by the fact that in terms of this experiment the chipping of the material is directly connected with its ability to resist the propagation of lateral as well as median cracks. According to Table $3 \mathrm{AO} 13 \mathrm{Al}$ ceramics have the highest fracture toughness, while $\mathrm{AO} 25 \mathrm{Al}$ has the worst one. It is worth mentioning that the data on the material 


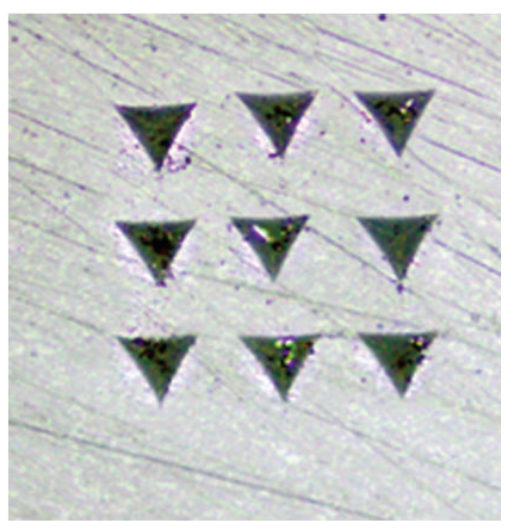

(a)

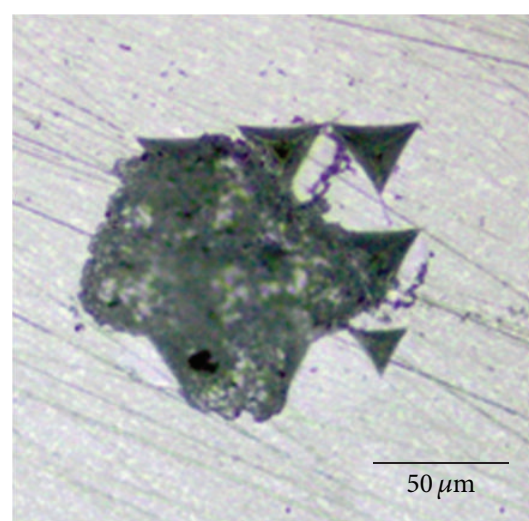

(b)

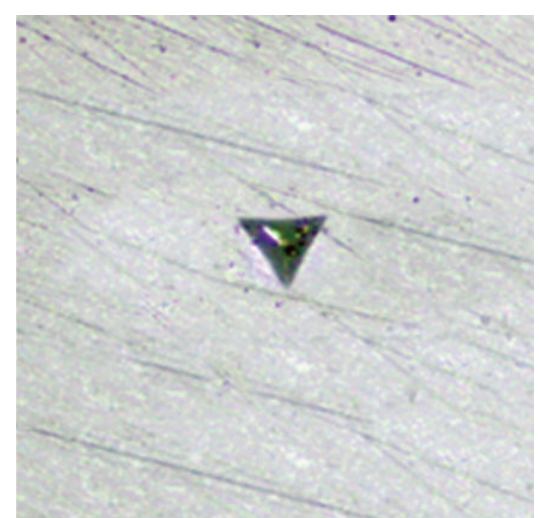

(c)

Figure 2: The impression images of AO25Al ceramics. The spacings are (a) $-50 \mu \mathrm{m},(\mathrm{b})-35 \mu \mathrm{m}$, and (c) $-0 \mu \mathrm{m}$ (9 indents at the same place).

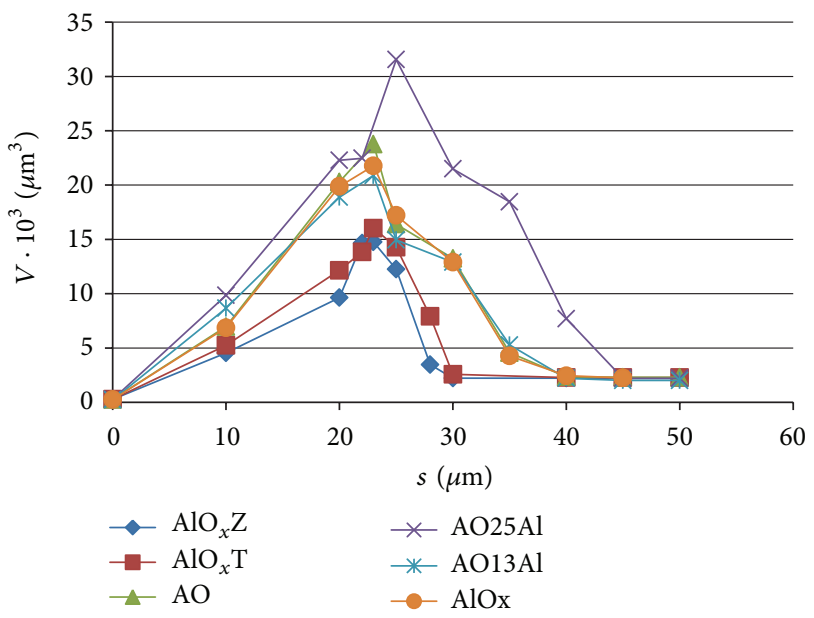

FIGURE 3: The influence of the indentation array spacing on the material loss of the ceramics.

loss from this work is in the good agreement with that from [14], where at $4,9 \mathrm{~N}$ load and $22,5 \mu \mathrm{m}$ spacing the volume of $23,5 \cdot 10^{3} \mu \mathrm{m}^{3}$ is chipped away from the surface of alumina ceramics.

Further improvement of the alumina ceramics wear resistance is found for the $\mathrm{AlO}_{x} \mathrm{Z}$ and $\mathrm{AlO}_{x} \mathrm{~T}$ composites (curves 5 and 6). Having the comparable to AO-based ceramics mechanical properties these composites have smaller grain size and higher level of structural homogeneity. This enhances the boundary resistance to cracking, leading to a noticeable decrease of the material lost down to $30 \%$.

As seen from Figure 3, the processing route of pure alumina powders did not influence their indentation wear resistance. The material lost in both cases is almost the same (curves 1 and 4). The slight increase of the material chipping for AlOx ceramics is connected with lower mechanical properties $\left(\gamma, H_{V}\right.$, and $\left.K_{\mathrm{IC}}\right)$ compared to $\mathrm{AO}$ ceramics (Table 3).

\section{Conclusions}

Different processing routes (MPC or HP) result in a comparable microstructure and mechanical properties of dense alumina-based ceramics. The addition of $\mathrm{Al}$ to the starting alumina powder leads to the decrease of the grain size of ceramics, but it has a negative effect on indentation wear resistance due to a high level of crystalline lattice microdistortions.

Homogeneous fine structure of $\mathrm{ZrO}_{2}$ or TiCN doped alumina improves $H_{V}, E, K_{\mathrm{IC}}$, and wear resistance of the composite compared to pure $\mathrm{Al}_{2} \mathrm{O}_{3}$ by $20-30 \%$.

\section{Acknowledgment}

This work was supported by the Russian Fund of Basic Research, Project no. 12-08-00976-a.

\section{References}

[1] D. Sherman and D. Brandon, "Mechanical properties of hard materials and their relation to microstructure," Advanced Engineering Materials, vol. 1, no. 3-4, pp. 161-181, 1999.

[2] B. Kerkwijk, E. Mulder, and H. Verweij, "Zirconia-alumina ceramic composites with extremely high wear resistance," Advanced Engineering Materials, vol. 1, no. 1, pp. 69-71, 1999.

[3] A. I. Gusev and A. A. Rempel, Nanocrystalline Materials, Cambridge International Science Publishing, 2004.

[4] H. Awaji, T. Matsunaga, and S.-M. Choi, "Relation between strength, fracture toughness, and critical frontal process zone size in ceramics," Materials Transactions, vol. 47, no. 6, pp. 15321539, 2006.

[5] A. A. Abramovich, O. V. Karban', V. V. Ivanov, and E. I. Salamatov, "Influence of the structure on the thermal conductivity of the $\mathrm{Al}_{2} \mathrm{O}_{3}+\mathrm{Fe}$ nanocomposite," Glass Physics and Chemistry, vol. 31, no. 5, pp. 709-711, 2005.

[6] M. Backhaus-Ricoult, V. Guérin, J. Deschamps, and B. Pellissier, "Increase in fracture toughness of monolithic ceramics by a partial reduction treatment," Key Engineering Materials, vol. 132-136, pp. 516-519, 1997.

[7] M. D. Snel, G. de With, F. Snijkers, J. Luyten, and A. Kodentsov, "Aqueous tape casting of reaction bonded aluminium oxide (RBAO)," Journal of the European Ceramic Society, vol. 27, no. 1, pp. 27-33, 2007. 
[8] I.-W. Chen and X.-H. Wang, "Sintering dense nanocrystalline ceramics without final-stage grain growth," Nature, vol. 404, no. 6774, pp. 168-171, 2000.

[9] V. V. Ivanov, S. N. Paranin, and V. R. Khrustov, "Nanostructured ceramics based on aluminum and zirconium oxides produced using magnetic pulsed pressing," Physics of Metals and Metallography, vol. 94, no. 1, pp. S98-S106, 2002.

[10] G. R. Anstis, P. Chantikul, B. R. Lawn, and D. B. Marshall, "A critical evaluation of indentation techniques for measuring fracture toughness: I, direct crack measurements," Journal of American Ceramic Society, vol. 64, pp. 533-538, 1981.

[11] A. Franco and S. G. Roberts, "Controlled wet erosive wear of polycrystalline alumina," Journal of the European Ceramic Society, vol. 16, no. 12, pp. 1365-1375, 1996.

[12] A. Kaygorodov and V. Khrustov, "The influence of $\mathrm{Al}_{2} \mathrm{O}_{3}+\mathrm{Al}$ powders stirring time on the quality of alumina-based ceramics," Epitoanyag, vol. 62, pp. 116-118, 2010.

[13] R. W. Siegel, "Nanostructured materials -mind over matter-," Nanostructured Materials, vol. 4, no. 1, pp. 121-138, 1994.

[14] I. P. Shapiro, R. I. Todd, J. M. Titchmarsh, and S. G. Roberts, "An indentation model for erosive wear in $\mathrm{Al}_{2} \mathrm{O}_{3} / \mathrm{SiC}$ nanocomposites," Journal of the European Ceramic Society, vol. 31, no. 1-2, pp. 85-95, 2011. 

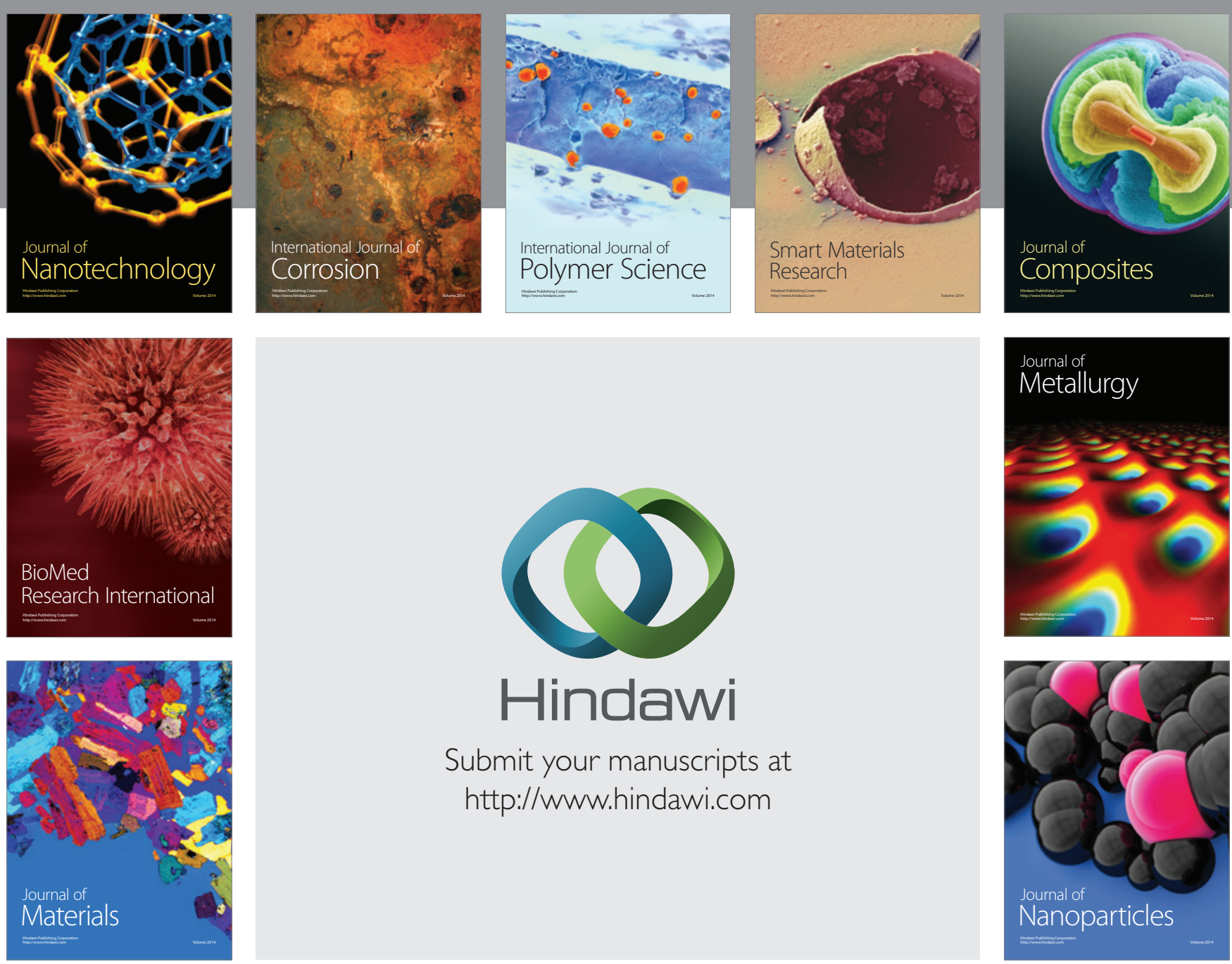

Submit your manuscripts at http://www.hindawi.com
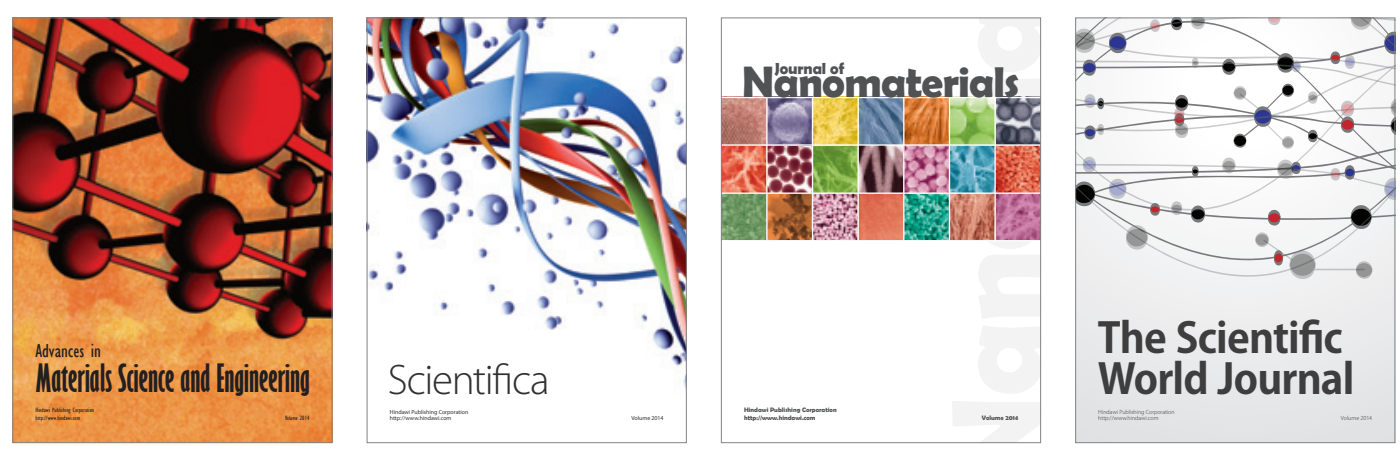

\section{The Scientific World Journal}
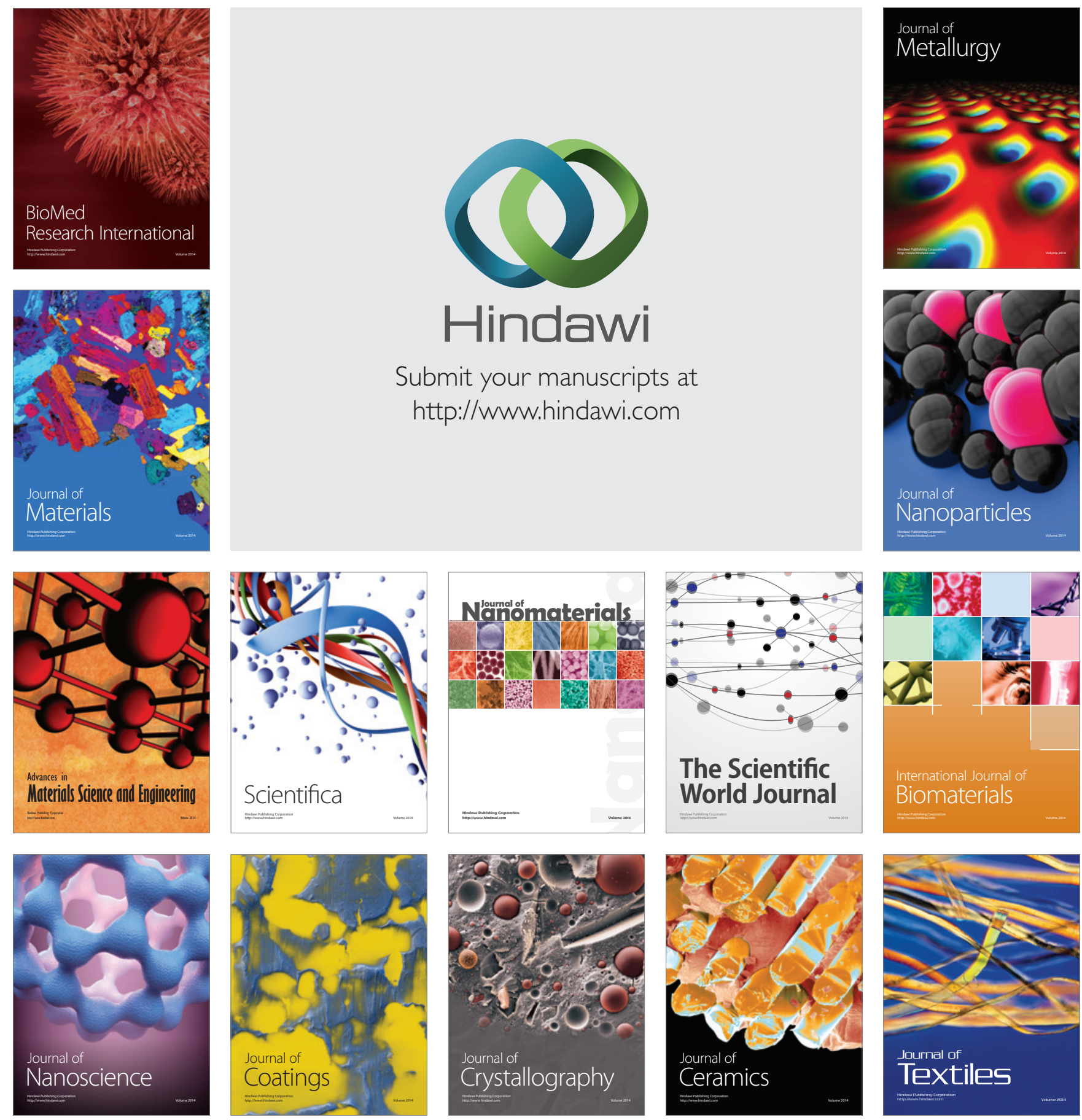